\title{
RATE OF APPROXIMATION OF BOUNDED VARIATION FUNCTIONS BY THE BÉZIER VARIANT OF CHLODOWSKY OPERATORS
}

\author{
BO-YONG LIAN
}

Abstract. In this paper the pointwise approximation of the Bézier variant of Chlodowsky operators for bounded variation functions is studied. By means of the analysis techniques and some results of probability theory, we obtain an estimate formula on this type approximation. Our results correct the mistake of Karsli and Ibikli [H. Karsli and E. Ibikli, Convergence rate of a new Bézier variant of Chlodowsky operators to bounded variation functions, J. Comput. Appl. Math 212 (2008) 431-443], and also extend the work of Zeng [X. M. Zeng, On the rate of convergence of two Bernstein-Bézier type operators for bounded variation functions II, J. Approx. Theory 104 (2000) 330-344].

Mathematics subject classification (2010): 41A36, 41A25, 41A10.

Keywords and phrases: Chlodowsky operators, Rate of convergence, Approximation, Bounded variation functions, Lebesuge-Stieltjes integral.

\section{REFERENCES}

[1] H. KARSLi AND E. IBIKLI, Convergence rate of a new Bézier variant of Chlodowsky operators to bounded variation functions, J. Comput. Appl. Math. 212 (2008), 431-443.

[2] X. M. ZENG, On the rate of convergence of two Bernstein-Bézier type operators for bounded variation functions II, J. Approx. Theory. 104 (2000), 330-344.

[3] X. M. ZENG AND A. PIRIOU, On the rate of convergence of two Bernstein-Bézier type operators for bounded variation functions, J. Approx. Theory. 95 (1998), 369-387.

[4] X. M. ZENG, Bounds for Bernstein basis functions and Meyer-König-Zeller basis functions, J. Math. Anal. Appl. 219 (1998), 364-376.

[5] A. N. ShIRYAYEV, Probability, Springer-Verlag, New York, 1984.

[6] G. G. Lorentz, Bernstein Polynomials, Univ. of Toronto Press, Tornoto, 1953.

[7] V. GuptA, An estimate on the convergence of Baskakov-Bézier operators, J. Math. Anal. Appl. 312 (2005), 280-288.

[8] P. PyCh-TABERSKA, Some properties of the Bézier-Kantorovich type operators, J. Approx. Theory. 123 (2003), 256-269. 